\title{
INTEGRATING MULTIPLE CRITERIA EVALUATION AND GIS IN ECOTOURISM: A REVIEW
}

\author{
Zulaikha Hana Mohd and Uznir Ujang \\ Department of Geoinformation, Faculty of Geoinformation and \\ Real Estate, Universiti Teknologi Malaysia, 81310, Skudai, Johor, \\ Malaysia-(eika_hanna@yahoo.com, mduznir@utm.my)
}

KEYWORDS : Ecotourism Development, Multiple Criteria Evaluation, Analytic Hierarcy Process, GIS.

\begin{abstract}
:
The concept of 'Eco-tourism' is increasingly heard in recent decades. Ecotourism is one adventure that environmentally responsible intended to appreciate the nature experiences and cultures. Ecotourism should have low impact on environment and must contribute to the prosperity of local residents. This article reviews the use of Multiple Criteria Evaluation (MCE) and Geographic Information System (GIS) in ecotourism. Multiple criteria evaluation mostly used to land suitability analysis or fulfill specific objectives based on various attributes that exist in the selected area. To support the process of environmental decision making, the application of GIS is used to display and analysis the data through Analytic Hierarchy Process (AHP). Integration between MCE and GIS tool is important to determine the relative weight for the criteria used objectively. With the MCE method, it can resolve the conflict between recreation and conservation which is to minimize the environmental and human impact. Most studies evidences that the GIS-based AHP as a multi criteria evaluation is a strong and effective in tourism planning which can aid in the development of ecotourism industry effectively.
\end{abstract}

\section{INTRODUCTION}

Ecotourism has played an important source of revenue for the country. But ecotourism should be balanced in terms of a clean environment without polluting and spoiling the natural beauty and also does not harm the surrounding population. Ecotourism is a type of tourism that continues to preserve, providing various facilities in areas with tourist attractions, either relating to attraction on the natural environment or ecology-made through the modernization of physical and social infrastructure in the region to become one of the economic activities that contribute to the national income besides to being able to improve the living standards of local communities. Strategic planning to develop ecotourism area is not measured in terms of the landscape only, but many factors should be considered such as topography, climate area, soil type and many more. This planning can be overcome by using a method in which the existence of AHP technique with the help of GIS. Tourism and Information technology are two of the most active motivators of the global economy growth.

\section{MULTIPLE CRITERIA DECISION ANALYSIS WITH AHP}

Multi Criteria Decision Analysis (MCDA) is a spatial decision problem that mostly involves a large set of feasible alternatives and multiple criteria evaluation. Usually most researchers make decision process by using GIS that recognized as a decision support system which can analyzing, designing, evaluating and prioritizing alternative decisions to ecotourism development. GIS also can obtained the information for decision making through a transformation process and combines the geographical data and the value judgments. MCDA provides a variety of collections with an efficient technique and structuring procedure to get a decision. Thus, decision making involves multi criteria evaluation (MCE) used to rank and achieve the priorities for the alternatives of a decision.
Multiple criteria evaluation is commonly relate and use the Analythic Hierarchy Process (AHP).Analytic Hierarchal Process (AHP) is an important technique to analyse land suitability that developed by Thomas L.Saaty and it is a measurement theory through pairwise comparisons in making a decision between alternatives and criteria needed to earn the scale of priorities. So, before AHP is implemented, all relevant criteria like slope, temperature, climate and soil types should be sufficient.

The importance and suitability established by ranking weights of specific criteria. With a strong knowledge and data can commonly be identified the weight of factor in AHP. AHP include some steps to untangle the decision with a more systematic way in which define the problem and draft the decision hierarchy from the top with the goal, through the intermediate until the lowest level (determine the criteria). Then, make a set pairwise comparison matrix and from the comparison need to use the priorities acquired to weight in the level immediately below. This is because to make it easier for decision makers to identify the relative weight and compute the quantitative to validate the result of land suitability.

\section{THE IMPORTANT OF MULTI CRITERIA EVALUATION IN ECOTOURISM DEVELOPMENT}

A criterion (factor) need to evaluated and measured for decision making. Selecting or formulating the criteria which is decision maker can choose several methods to determine the weight of each factor such as by ranking, rating and Analytic Hierarchy Process. Many discussion on AHP in ecotourism by researchers in which Bali et al. (2015) in Iran give comments the criteria like slope and aspect is significant for ecotourism development and could not be neglected. Likewise, same reported from Buruamkaew and Muruyam (2011) in Thailand. A review represent the steep areas with a slope more than $>45 \%$ is a limiting factor for ecotourism activities. They conclude slope 
with $>15 \%$ could be appropriate criteria. According to Geremew and Hailemeriam (2015) in Ethiopia, mostly ecotourism take place in historical resources, natural area and traditional culture. Thus, the criteria of road distance must be considered with regard to the natural area. Another research result by Kumari et al. (2010) in Malaysia suggest that ecotourism activities influenced by climatic condition. So, the climate factor must be investigate to obtain the suitable ecotourism land. Soil features also give greatly effect to tourist activities. So, the type and texture of soil need to determine first to avoid and spoil the tourist activities.

Based on AHP method, the weight of influencing factor have determined through pairwise comparison matrix. According to Saaty (1980) in USA, construct a matrix where each factor need to compared with the other factor and make a scale from 1 to 9 which is 1 is equal preference and 9 is extreme importance. The table below show the fundamental scale for factor used by Saaty (1980).

Table 1 : The fundamental scale for factor used, source by Aburas et al. (2015) from Asian Journal of Applied Sciences

\begin{tabular}{|c|c|c|}
\hline $\begin{array}{l}\text { Intensity of } \\
\text { importance }\end{array}$ & Description & Suitability class \\
\hline 1 & Equal importance & $\begin{array}{c}\text { Lowest } \\
\text { suitability }\end{array}$ \\
\hline 2 & $\begin{array}{l}\text { Equal to moderate } \\
\text { importance }\end{array}$ & $\begin{array}{c}\text { Very low } \\
\text { suitability }\end{array}$ \\
\hline 3 & $\begin{array}{c}\text { Moderate } \\
\text { importance } \\
\end{array}$ & Low suitability \\
\hline 4 & $\begin{array}{c}\text { Moderate to strong } \\
\text { importance }\end{array}$ & $\begin{array}{c}\text { Moderately low } \\
\text { suitability }\end{array}$ \\
\hline 5 & Strong importance & $\begin{array}{l}\text { Moderate } \\
\text { suitability }\end{array}$ \\
\hline 6 & $\begin{array}{c}\text { Strong to very } \\
\text { strong importance }\end{array}$ & $\begin{array}{c}\text { Moderate high } \\
\text { suitability }\end{array}$ \\
\hline 7 & $\begin{array}{l}\text { Very strong } \\
\text { importance } \\
\end{array}$ & High suitability \\
\hline 8 & $\begin{array}{l}\text { Very to extremely } \\
\text { strong importance }\end{array}$ & $\begin{array}{l}\text { Very high } \\
\text { suitability }\end{array}$ \\
\hline 9 & $\begin{array}{c}\text { Extreme } \\
\text { importance }\end{array}$ & $\begin{array}{c}\text { Highest } \\
\text { suitability }\end{array}$ \\
\hline
\end{tabular}

Then, make the weight normalization and calculate the consistency ratio (CR). The formula as shown in equation (1) and (2).

$$
C R=\frac{C I}{R I}
$$

Where Consistency Ratio (CR) equal Consistency index (CI) / Random Consistency Index (RI).

$$
S i=\sum_{i=1}^{n}(W i \times R i)
$$

Where (Si) is composite suitable score, (n) is number of factor, (Wi) refer to weight of factor and (Ri) is a rating for determine the class of $i$ factor.

If CR larger than $>0.10$, then the value of pairwaise need to be repeate in evaluation process until get the acceptable value of CR smaller than $<0.10$ for suitability analysis.

The weighting process of each factor involved multi criteria map and standardize and weighted the factor by decision maker that need to decide based on knowledge and fair judgement to produce the result of ecotourism region.

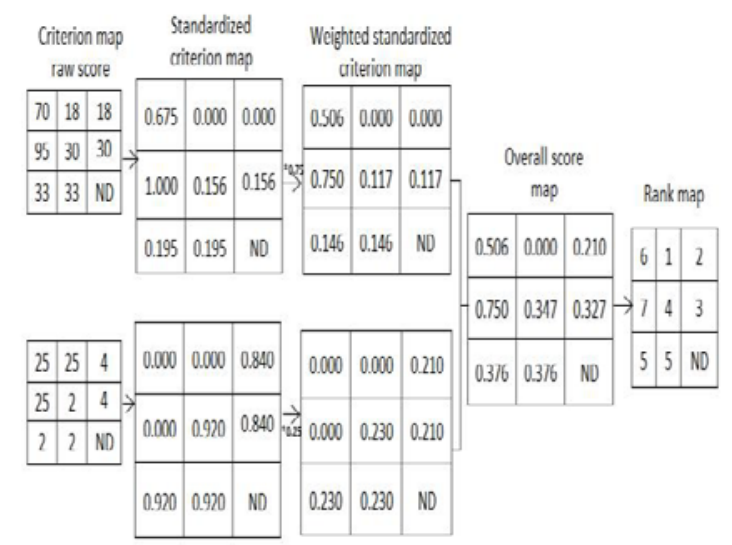

Figure 1. Simple weighting process implemented in GIS adopted from (Malczewski 2009)

\section{METHOD AND FRAMEWORK OF LAND SUITABILITY ANALYSIS}

Determine the criteria for selecting appropriate ecotourism area need more measurable and alternative. Based on past papers, a lots of input data or factors need to collect such as topography map, climate data, types of soil knowledge and land use include distance from road, water resources and population. All data can obtained from any sources like private and government company that fullfill and related with ecotourism area characteristics. Then, standardize the criterion value to common scale to make the comparison and continue it by using AHP method to detemine the weight factor. The last one, the suitability map of ecotourism area is created and verify the result by conduct a field survey or ground truth.

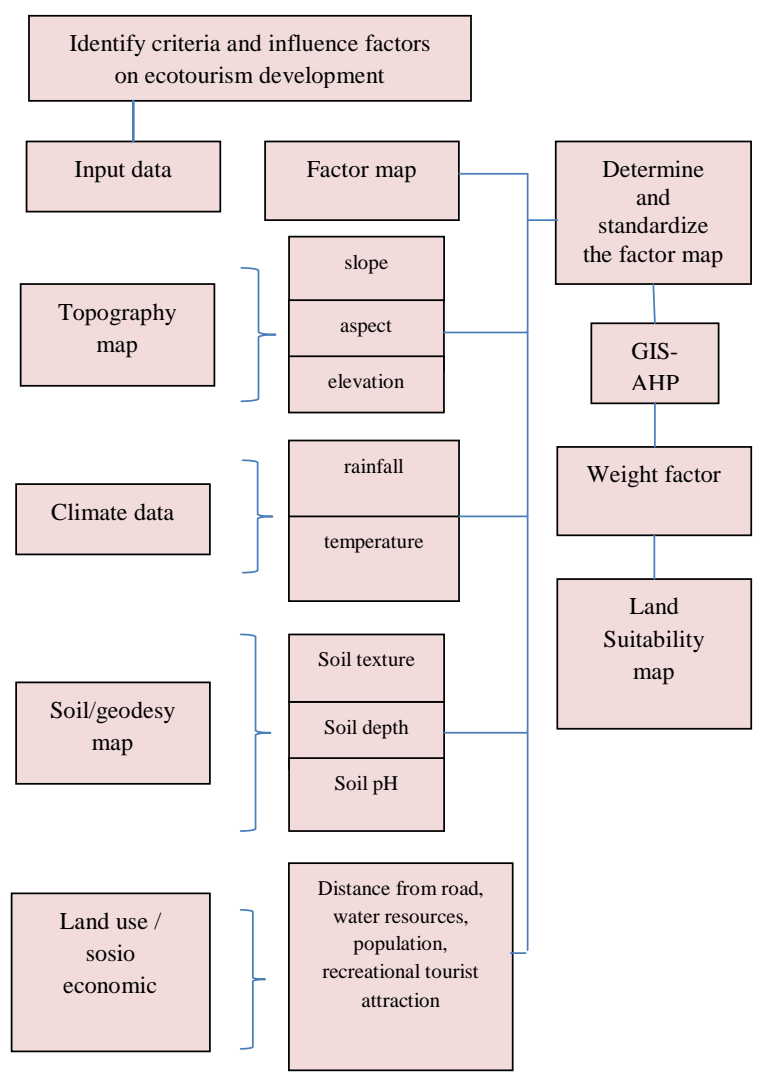

Figure 2 : The framework of land suitability assessment 
The figure below show the result obtained from Bali et.al (2015), the distance from water resources, slope and land use are the highest ranking score. The Hyrcanian forest and Anzali Wetland give a special consideration due to ecological condition. This area very suitable for ecotourism place because there is exists the fragile ecosystem and forest as protected area covered Anzali region that fall in the red one.

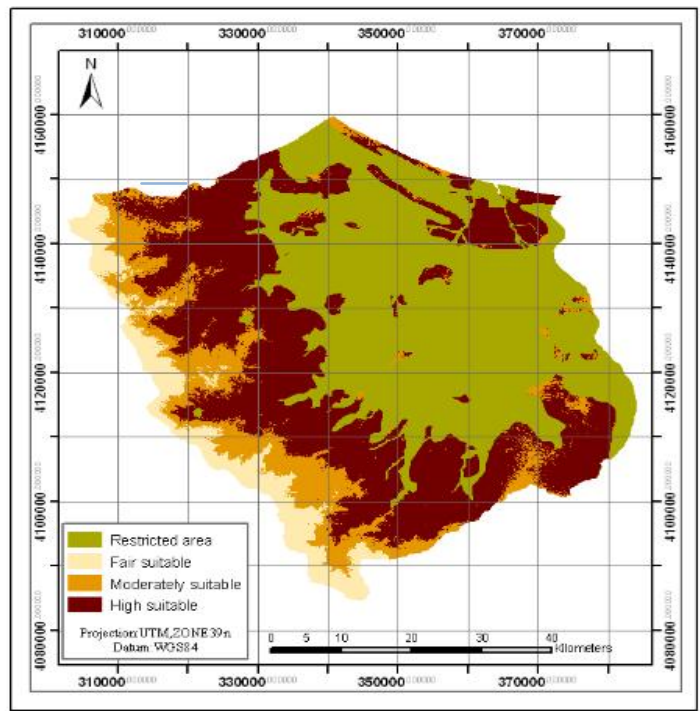

Figure 3 : Land suitability for ecotourism development in

Anzali Watershed copyright from Bali et al. (2015)

In the map below (figure 4) shows the hilly forest region which is highly suitable area but has some parts not highly suitable due to low density of forest. For this case, decision makers select the suitable ecotourism area base on the priority of nature (forest). Potential to be ecotourism area must be considered by any factors where has existing development like infrastructures, accomodation and tourist's civic services and high population. It prooved that the purple colour fall near the red bullet (existing tourist spot).

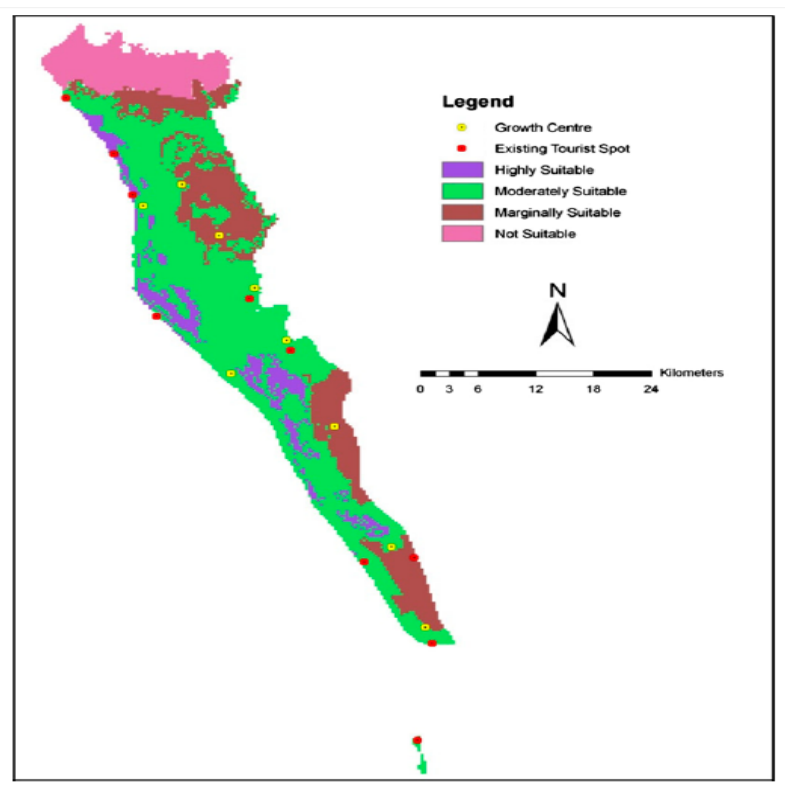

Figure 4 : Land suitability for map ecotourism in Cox’ Bazar, Source by Ullah and Hafiz (2014)

\section{SUMMARY}

In order to evaluate the ecotourism place, the effective criteria should be identified first. Those multiple criteria evaluation is very significant for making decision that can be used in any methods in GIS tool other than AHP method. MCE also is a best complex scenarios in which involve a lot of consideration. The criteria of evaluation need to standardized and weighted to achieved the best location for ecotourism area and successful applied by many researchers.

\section{REFERENCES}

Abdolreza Roknoddin Eftekhari, Hamdollah Sojasi Qidari, Mehdi Purtaheri, Adel Azar, 2013. Application of Integration Multi-Criteria Decision Making Method and GIS in Identification of Rural Regions with Ecotourism Potential Case Study: River Valley Tourism in Tehran Providence, Rural Research 2013 4, (3) pp.641-Pe660.

Aleksandar Rikalovic, Ilija Cosic, Djordje Lazarevic,2014. GIS Based Multi-Criteria Analysis for Industrial Site Selection, Univrsity of Novi Sad, Faculty of Technical Sciences, pp. 1054-1063.

Ali Baba, Seyed Masoud Monavari , Borhan Riazi , Nematollah Khorasani , Mir Masoud Kheirkhah Zarkesh , 2015. A spatial decision support system for ecotourism development in caspian hyrcanian mixed forests ecotourism region, Department of the Environmental Science Faculty of the Environment and Energy Tehran Science and Research Branch Islamic Azad University.

Ali Mahdavi, Maryam Nik. Nejad, 2014. Site suitability evaluation for ecotourism using MCDM methods and GIS: Case study Lorestan province, Iran. Journal of Biodiversity and Environmental Sciences (JBES),4,(6), pp.425-437.

Barbosa O, Tratalos JA, Armsworth PR, Davies RG, Fuller RA, Johnson P, Gaston KJ. 2007. Who benefits from access to green space? A case study from Sheffield, UK. Landscape and Urban Planning, 83, pp.187-195.

Bagus Tri Nugroho, Arief Rosyidie, Sato Keisuke, Zoning Design for Sustainable Ecotourism Development in Bogani Nani Wartabone National Park, Indonesia Jurnal Perencanaan Wilayah dan Kota B SAPPK, pp.1-17.

Ceballos-Lascurain, H. Tourism, ecotourism and protected areas. Gland, Switzerland: IUCN. 1996.

Chi Chen, Chao Chen, Xiaolong Sun,2012. Application of GIS Digital Technology in Planning of Tourism Scenic Spot. Applied Mechanics and Materials, Vols. pp. 204-208.

Duong Dang Khoi, Yuji Murayama, 2010. Delineation of Suitable Cropland Areas Using a GIS Based Multi-Criteria Evaluation Approach in the Tam Dao National Park Region, Vietnam, University of Tsukuba, 2024-2043.

Heshmat Piran, Rahim Maleknia, Hassan Akbari, Javad Soosani, Omid Karami, 2014. Siteselection for local forest park using analytic hierarchy process and geographic information system (case study: Badreh County). International Research Journal of Applied and Basic Sciences , 6 (7), pp.930-935. 
Hsu,.T.K., Tsai, Y.F. and Wu, H.H. (2009). The preference analysis for tourist choice of destination: A case study of Taiwan. Tourism Management Journal 30, pp. 288-297.

Khwanruthai Bunruamkaew, Yuji Murayama in 2011. Site Suitability Evaluation for Ecotourism Using GIS \& AHP: A Case Study of Surat Thani Province, Thailand, International Conference: Spatial Thinking and Geographic Information Sciences 2011, 21, pp, 269-278.

Kumari, S.; Behera, M. D.; Tewari, H. R. Identification of potential ecotourism sites in West District, Sikkim using geospatial tools. Tropical Ecology, v.51, n.1, p.75-85, 2010.

Kurttila M, Pesonen M, Kangas J, Kajanus M.2000. Utilizing the analytic hierarchy process (AHP) in SWOT analysis-a hybrid method and its application to a forest- Certification case. Forest Policy and Economics 1(1) pp.41-52.

Mahsa Liaghat, Himan Shahabi, Bashir Rokni Deilami, Farshid Sattari Ardabili, Seyed Navid Seyedi, Hadi badri, 2013. A Multi-Criteria Evaluation using the Analytic Hierarchy Process Technique to Analyze Coastal Tourism Sites, pp.479-485.

Manijeh Ghahroudi Tali, Seyed Hasan Sadough, Mohammad , 2012. Multi-criteria evaluation to select sites for ecotourism facilities: a case study Miankaleh Peninsula. An International Journal of Tourism and Hospitality Research, 23, pp.373-394.

Malczewski, J 2009, 'GIS and Multicriteria Decision Analysis', in Chapter 6, ed. J Malczewski, John Wiley \& Sons, Inc., Various.

M.Mokarram, F.Aminzadeh, 2013, GIS-based multicriteria land suitability evaluation using ordered weight averaging with fuzzy quantifier: A case study in Shavur Plain,Iran.

OK.K, 2005. Multiple Criteria Activity Selection for Ecotourism Planning in igneada, pp.153-164.

Saaty TL.1980.The analytic hierarchy process, McGraw-Hill, New York, Mathematical Modelling, 9,(3-5),pp. 161-176.

Sehnaz Sener, Erhan Sener, Bitgehan Nas, Remzi Karaguzel, 2010. Combining AHP with GIS for landfill site selection: A case study in the Lake Beyşehir catchment area (Konya,

Turkey), 30,(11).

S. Kumari, M.D. Behera \& H.R. Tewari, 2010, Identification of potential ecotourism sites in West District, Sikkim using geospatial tools. International Society for Tropical Ecology. 51(1),pp. 75-85,

T. Fung and F.K.-K.Wong, 2007. Ecotourism planning using multiple criteria evaluation with GIS. Geocarto International,22 (2), pp. 87-105.

Wang Cuirong,Yang Zhaoping,Liu Huaxian,Han Fang,Xia Wenjin, 2016. Campgrounds Suitability Evaluation Using GISbased Multiple Criteria Decision Analysis: A Case Study of Kuerdening, China, 8, (1) 